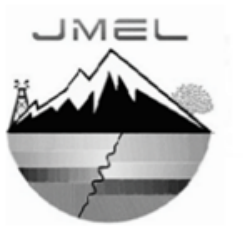

\title{
Geologi dan Manivestasi Tektonik Gayaberat Gunung Pawinihan di Kabupaten Banjarnegara Jawa Tengah
}

\author{
Sari Bahagiarti Kusumayudha ${ }^{1, \text { a), Heru Sigit Purwanto }}{ }^{\text {1, b) }}$ \\ 1) Teknik Geologi, Fakultas Teknologi Mineral, Universitas Pembangunan Nasional Veteran Yogyakarta \\ a) Email korespondensi: saribk@upnyk.ac.id \\ b) sigitgeologi@hotmail.com
}

\begin{abstract}
ABSTRAK
Gunung Pawinihan, sebuah kerucut gunungapi purba, berada di tapal batas antara Kecamatan Karangkobar dan Kecamatan Banjarmangu, Kabupaten Banjarnegara, Jawa Tengah. Secara astronomis, puncak gunung tersebut terletak pada titik potong antara garis $109^{\circ} 41^{\prime} 35^{\prime}$ Bujur Timur dan garis $7^{\circ} 18^{\prime} 51^{\prime}$ Lintang Selatan. Dalam pembagian fisiografi Jawa Tengah, gunung ini termasuk di Zona Pegunungan Serayu Utara. Penelitian ini bertujuan untuk menganalisis gerakan-gerakan massa di Gunung Pawinihan berdasarkan kajian geologis dan geomorfologis. Batuan alas Gunung Pawinihan adalah Formasi Merawu, terdiri dari napal, serpih, batulempung berselingan dengan batupasir gampingan, berumur Miosen Tengah (N12 - N13). Sementara itu penyusun tubuh Gunung Pawinihan adalah endapan vulkanik yang secara regional merupakan Formasi Jembangan, tersusun atas lava dan breksi piroklastik dengan komposisi andesit piroksen serta andesit olivin, berumur Plestosen. Pada tubuh Gunung Pawihinan dijumpai sesar-sesar normal berjenjang dengan jurus Timurlaut-Baratdaya. Bagian-bagian tubuh serta lereng-lereng gunung inipun acap runtuh sebagai manivestasi gaya berat massa yang berada pada bidang miring. Gerak-gerak gravitasional tersebut berupa longsoran dan lengseran tubuh Gunung Pawinihan dengan arah umum ke Tenggara menuju lembah Kali Urang - Kali Merawu, anak Sungai Serayu di Selatan daerah penelitian. Peristiwa longsor besar terakhir terjadi pada tanggal 4 Januari 2006 , menimbulkan kerugian dan menewaskan sekitar 100 orang penduduk di desa Sijeruk.
\end{abstract}

Kata Kunci: endapan vulkanik; longsor; sesar berjenjang; tektonik gayaberat

\begin{abstract}
Mount Pawinihan, an ancient volcanic cone is located on the boundary between Karangkobar District and Banjarmangu District, Banjarnegara Regency, Central Java. Astronomically, the summit of this mountain is located at the intersection point of lines 109 41'35" East Longitude and $7^{\circ} 19^{\prime} 51^{\prime \prime}$ South Latitude. In the physiographic division of Central Java, this mountain is included in the North Serayu Mountain Zone. This study was aimed to analyze the mass movements in Pawinihan Mount based on geological and geomorphological studies. The baserocks of Mount Pawinihan is Merawu Formation, consisting of marl, shale, claystone interlocked with calcareous sandstone of Middle Miocene (N12 - N13) age. Meanwhile, the composition of Mount Pawinihan body is volcanic deposits, consisting of lava and pyroclastic breccias with composition of pyroxene andesite and olivine andesite, regionally belongs to the Jembangan Formation which are Pleistocene-aged. There are normal step faults on the body of Mount Pawihinan with NortheastSouthwest strikes. Parts and slopes of this mountain are also often collaps as the manivestation of weight force of a mass positioning over an incline field. The gravitational movements are in the form of avalanches and slidings of Mount Pawinihan with general direction to the Southeast towards the Kali Urang - Kali Merawu valleys, the tributary of Serayu River in the South of the study area. The last major landslide occurred on January 4, 2006, causing losses and killing around 100 residents in the village of Sijeruk.
\end{abstract}

Keywords: gravitational techtonic; slides; step faults; volcanic deposits

\section{PENDAHULUAN}

Gunung Pawinihan, sebuah kerucut gunungapi purba, merupakan salah satu jejak erupsi eksentrik dari kompleks Rogo Jembangan (Van Bemmelen, 1949). Gunung ini terletak pada perbatasan antara Kecamatan Karangkobar dan Kecamatan Banjarmangu, Kabupaten Banjarnegara, Jawa Tengah. Secara astronomis, berdasarkaan Google Earth, pada saat ini puncak Gunung Pawinihan berada di perpotongan antara garis-garis 109 41 '35" Bujur Timur dan $7^{\circ} 18^{\prime} 51^{\prime \prime}$ Lintang Selatan, dapat diakses melalui jalan raya Banjarnegara - Karangkobar (Gambar 1). Untuk mendaki hingga ke puncak, dapat dilakukan lewat desa Sijeruk atau desa Telaga. Selain sebagai lahan budidaya hutan pinus Perhutani, gunung ini dimanfaatkan oleh masyarakat sebagai tempat wisata minat khusus, yaitu pendakian bagi para pecinta alam. Di bagian lereng gunung tersebut terdapat beberapa desa cukup padat penduduknya, salah satu di antaranya adalah desa Sijeruk, Kecamatan Banjarmangu. 
Tanah longsor sering terjadi di Gunung Pawinihan. Tubuh gunung ini diduga selalu bergerak, bahkan telah bergeser dari posisi awalnya, dengan kecepatan $120 \mathrm{~cm}$ dalam waktu 5 tahun, atau $24 \mathrm{~cm} /$ tahun ke arah selatan menjauhi induknya, Gunung Jembangan (Van Bemmelen, 1949). Hal ini disebabkan oleh adanya peristiwa gliding tectonics yang berlangsung pada geantiklinal Serayu Utara (Van Bemmelen, 1949, De Jong, 1973, Husein dkk, 2013). Pada kenyataannya, sesuai rekaman sejarah, catatan masyarakat, dan hasil penelittian para pakar, gunung ini acap kali mengalami longsor pada bagian lereng-lerengnya, baik dalam skala besar maupun kecil (Hidayat, 2018, Hutomo \& Maryono, 2017, Kusumayudha \& Purwanto 2020, Naryanto, 2017). Longsoran besar terakhir terjadi pada tanggal 4 Januari 2006 menimbun sebuah permukiman, menewaskan sekitar 100 korban jiwa di desa Sijeruk Kecamatan Banjarmangu (Kusumayudha \& Purwanto 2020).

Uraian di atas telah melatarbelakangi penelitian ini, dalam kerangka mengkaji proses geologis dan geomorfologis yang terjadi pada Gunung Pawinihan. Adapun tujuan penelitiaan adalah untuk menganalisis gerakan-gerakan massa di Gunung Pawinihan berdasarkan kajian geologis dan geomorfologis, agar dapat dijadikan sebagai bahan informasi, dan referensi bagi semua pihak yang memerlukannya, serta untuk rujukkan dalam upaya mitigasi bencana.

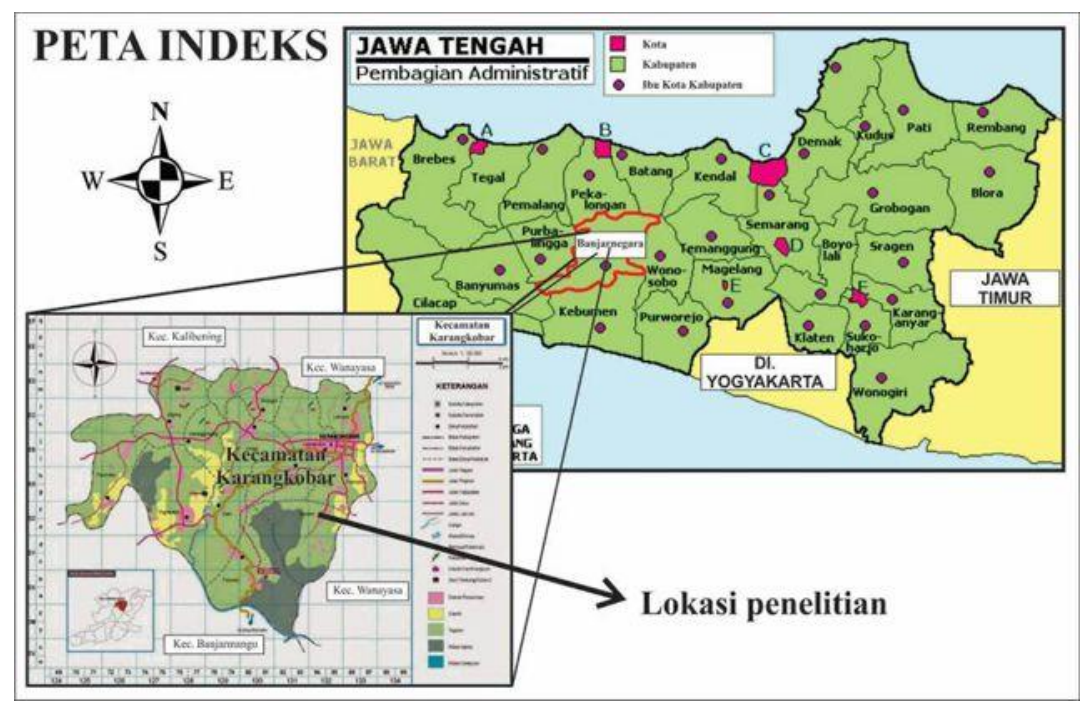

Gambar 1. Peta Lokasi Daerah Penelitian

\section{METODE}

Penelitian terhadap manivestasi gaya berat yang terjadi pada Gunung Pawinihan dilaksanakan dengan pendekatan perpaduan metode-metode diskriptif, analitik, komparatif, survei lapangan, dan analisis laboratorium, memanfaatkan baik data primer maupun data sekunder. Data primer yang digunakan berupa data geologis, stratigrafi, petrologi, sfat fisik batuan, struktur geologi, dan geomorfologi yang diperoleh dari survei dan pemetaan di lapangan. Data sekunder terdiri dari kepustakaan dan peta geologi regional, peta topografi, geologi teknik hasil penelitian terdahulu, dan citra satelit (Google earth).

Pelaksanaan survei dan pemetaan geologi dilengkapi dengan pengukuran kedudukan struktur geologi, identifikasi ekspresi morfologi serta kejadian longsor. Analisis petrologi dan petrografi dilakukan untuk menentukan nama batuan penyusun, dan satuan batuan yang berada di bawah Gunung Pawinihan, struktur geologi meliputi klasifikasi jenis sesar, dan uji sifat fisik digunakan untuk menentukan berat jenis (specific gravity) batuan. Khusus analisis geomorfologi, sarana penunjang yang digunakan antara lain peta topografi dan peta citra satelit Google Earth.

\section{HASIL DAN PEMBAHASAN}

\subsection{Geologi}

Secara fisiografi Gunung Pawinihan berada di dalam Zona Serayu Utara bagian tengah (Gambar 2). Zona Serayu Utara merupakan sebuah geantiklinal, dipisahkan dengan Zona Serayu Selatan oleh lembah aliran Kali Serayu (Van Bemmelen, 1949). Gunung berketinggian $1252 \mathrm{~m}$ dpl ini bertumpu di atas topografi bergelombang dengan kemiringan $2 \%$ hingga $8 \%$ (atau lebih-kurang $2^{\circ}$ hingga $5^{\circ}$ ). Morfologi Gunung Pawinihan berupa kerucut terdenudasi, memanjang, 
48 ISSN 2549-7197 (cetak), ISSN 2549-564X (online)

JMEL, Volume 4 Nomor 2, 2020

dengan sumbu berorientasi Baratlaut - Tenggara (Gambar 3). Kemiringan lereng berkisar antara 30\% sampai dengan $80 \%\left(16^{\circ}-40^{\circ}\right)$, beda tinggi antara bagian kaki dan puncaknya adalah $500 \mathrm{~m}$ hingga $600 \mathrm{~m}$.

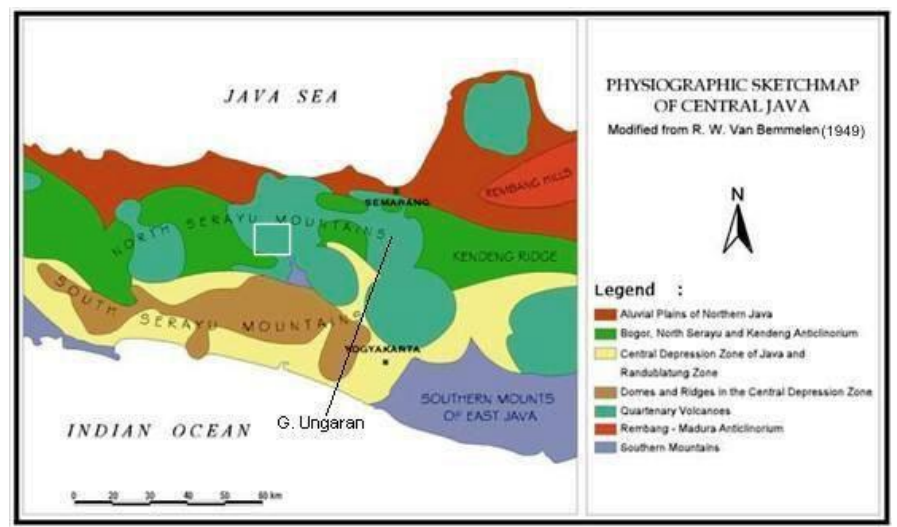

Gambar 2. Peta Fisiografi Jawa Tengah (Van Bemmelen, 1949), daerah Penelitian berada pada Zona Serayu Utara

Berdasarkan klasifikasi Dessaunettes (1977), geomorfologi di daerah penelitian dapat dibagi menjadi Satuan Morfologi Gunung dan Satuan Morfologi Bergelombang (Gambar 4). Sistem penyaliran membentuk pola radier dengan stadium muda, ditandai oleh adanya lembah-lembah berbentuk "V", dan arus sungai yang masih mengalir di atas batuan dasarnya (bedrock stream). Alur-alur pengering Gunung Pawinihan bermuara ke Kali Urang di sebelah timur dan sebagian bermuara ke Kali Merawu di selatan.

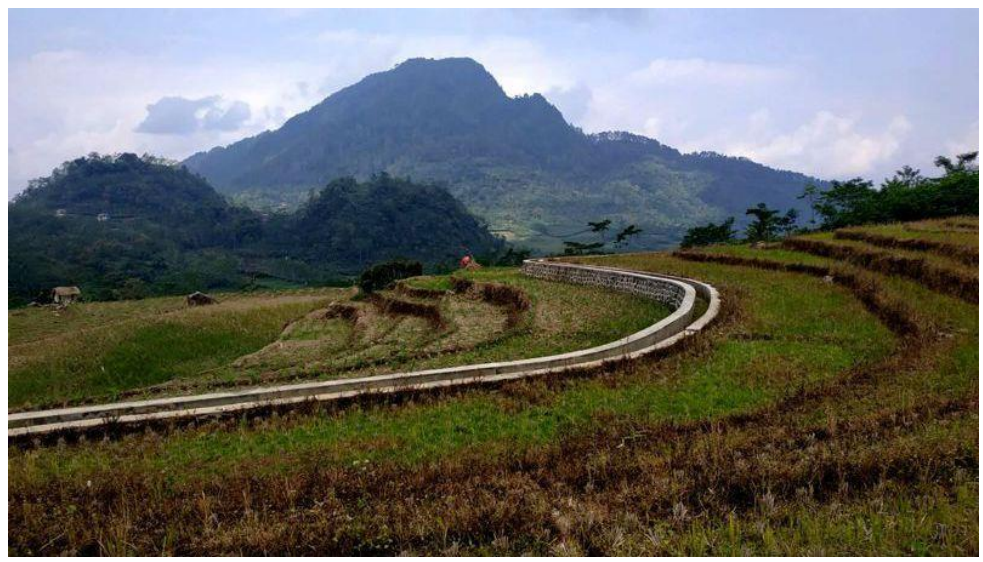

Gambar 3. Bentang Alam Gunung Pawinihan (Survei, 2020) 


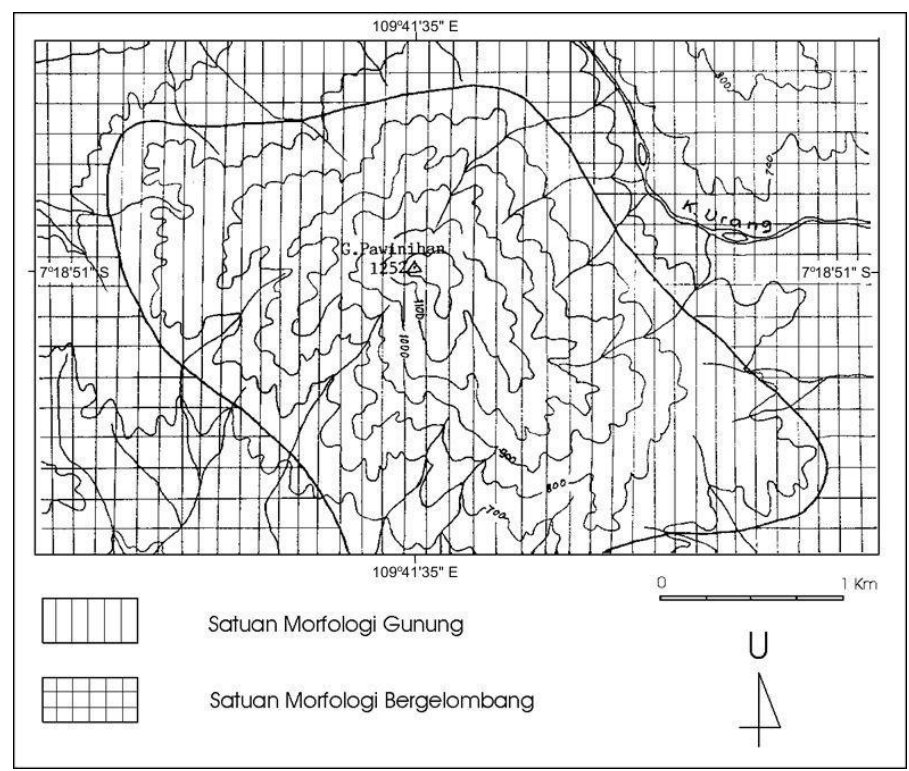

Gambar 4. Peta Morfologi Gunung Pawinihan

Secara stratigrafi Gunung Pawinihan menumpang tidak selaras di atas Formasi Merawu. Formasi Merawu merupakan endapan turbidit, terdiri dari napal, serpih, batulempung beselang-seling dengan batupasir gampingan (Bachri, 2010, 2012). Pada bagian bawah formasi ini terdapat konglomerat dan batugamping, sedangkan bagian atas didominasi oleh batupasir (Martosuwito, dkk, 2018). Dijumpai pula adanya struktur-struktur sedimen graded bedding, laminasi paralel, laminasi konvolut, dan flute cash. Berdasarkan diketemukannya Orbulina universa, Orbulina bilobata, Globigerina praebulloides, Globigerina immaturus, Globorotalia fohsi, Globorotalia seminulina, dan Globorotalia menardii, di daerah penelitian, maka dapat disimpulkan bahwa umur Formasi Merawu di daerah penelitian adalah Miosen Tengah (Blow, 1969). Fosil-fosil bentonik terdiri dari Nodosaria sublineata, Pseudoglandulina comaluta, Articulia sagra D'orbigny yang terkandung di dalam Formasi Merawu menunjukkan lingkungan laut dengan kedalaman antara $300 \mathrm{~m}-$ $500 \mathrm{~m}$ (Phleger, 1951).

Di atas Formasi Merawu, secara tidak selaras terdapat endapan vulkanik penyusun Gunung Pawinihan. Batuan ini merupakan anggota Formasi Jembangan, terdiri dari lava, breksi piroklastik, dan sisipan-sisipan tufa, serta lava. Secara petrologi satuan ini merupakan andesit, mengandung piroksen dan olivin sampai dengan $8 \%$. Lava menempati bagian bawah endapan vulkanik Pawinihan, dapat dijumpai di bagian kaki gunung ini di tepi jalan Banjarnegara - Karangkobar dan di jalan Sijeruk - Sijenggung. Piroklastika aliran maupun jatuhan dapat dijumpai di sebagian besar tubuh Gunung Pawinihan. Di bagian puncak gunung terdapat breksi lava atau autobreccia, diperkirakan merupakan sisa-sisa pusat erupsi gunung ini di masa lampau. Umur endapan vulkanik Pawinihan menurut Van Bemmelen (1949) adalah Plestosen Tengah hingga Plestosen Akhir. Berdasarkan analisis petrografi, komposisi mineralogi Endapan Vulkanik Pawinihan adalah sebagaimana tercantum di dalam Tabel 1 di bawah ini.

Tabel 1. Mineralogi Endapan Vulkanik Pawinihan

\begin{tabular}{ll}
\hline Mineral & Persentase (\%) \\
\hline Plagioklas An 48 (Andesin) sebagai massa dasar & $53-60$ \\
Plagioklas An 52 (Labradorit) sebagai fenokris & $6-10$ \\
Augit sebagai massa dasar & $20-25$ \\
Hipersten sebagai fenokris & $0-8$ \\
Olivin sebagai fenokris & $0-8$ \\
Mineral bijih & $5-8$ \\
\hline
\end{tabular}

Strukturr geologi yang terdapat di daerah penelitian berupa antiklin dengan sumbu berorientasi Baratlaut - Tenggara, sesar naik, dan sesar-sesar normal. Berdasarkan interpretasi geomorfologis terhadap peta topografi dan citra satelit 
Google Earth (Gambar 5), pada tubuh Gunung Pawinihan terdapat pola-pola kelurusaan dengan arah Timurlaut Baratdaya.

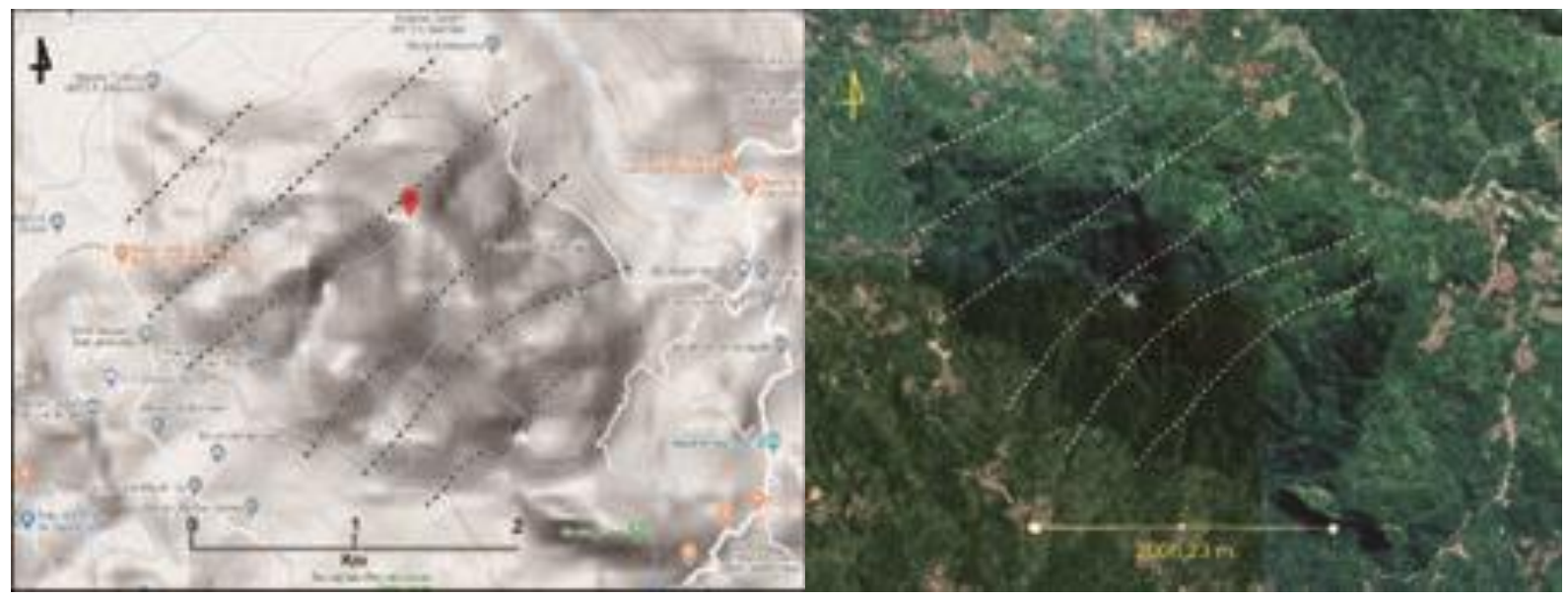

Gambar 5. Peta Topografi dan Citra Satelit Gunung Pawinihan dan sekitarnya (Sumber: Google Earth)

Selain hasil interpretasi tersebut, pada tubuh Gunung Pawinihan dijumpai gawir-gawir terjal, merupakan penanda telah terjadinya gerakan-gerakan vertikal sebagai akibat dari hadirnya sesar. Gawir-gawir pada tubuh Pawinihan mempunyai keterjalan mencapai $50^{\circ}$ (Gambar 6).

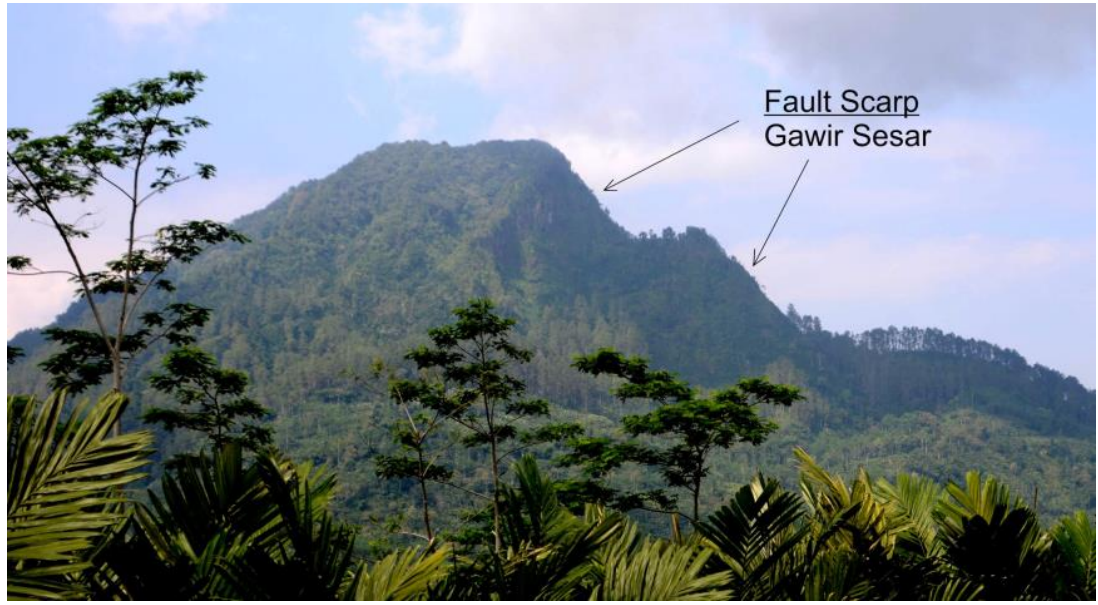

Gambar 6. Gawir Sesar pada Tubuh Gunung Pawinihan Bagian Tenggara (Survei, 2020)

Didasarkan atas interpretasi geomorfologis terhadap peta topografi dan citra satelit, terdapatnya gawir sesar dan triangular faset, maka dapat ditentukan bahwa pada tubuh Gunung Pawinihan terdapat 6 (enam) sesar normal. Tiga sesar mempunyai jurus Timurlaut-Baratdaya, sesar normal ekstensional, dan tiga sesar memiliki jurus Baratdaya-Timurlaut sesar normal bertangga (Gambar 7). Semua blok sesar yang menghadap puncak gunung (footwall) bergerak relatif turun terhadap blok yang menghadap kaki gunung (hangingwall) (Gambar 8).

Di sisi lain, Formasi Merawu sebagai batuan tumpuan Gunung Pawinihan mengalami perlipatan membentuk antiklin dengan sumbu Baratlaut - Tenggara, sesuai dengan alur lembah Kali Urang. Selain antiklin, dijumpai pula sesar naik dengan jurus paralel terhadap sumbu antiklin, blok baratdaya relatif naik, dengan kemiringan bidang sesar diduga mengikuti orientasi perlapisan Formasi Merawu. Struktur antiklin di daerah penelitian secara topografik berupa lembah, hal ini menandakan telah terjadi pembalikan topografi, membuktikan bahwa proses gliptogenesis yang berkerja terhadap Formasi Merawu telah berlangsung lanjut.

Sesar-sesar normal berjenjang di bagian Baratlaut Pawinihan menunjukkan adanya gaya ekstensional akibat adanya gerakan ke arah berlawanan, yaitu Tenggara, yang secara topografi lebih rendah, berupa lembah Kali Merawu. Di tempat tersebut terdapat sesar naik Kali Merawu yang juga memotong Formasi Bodas (Condon, dkk, 1996, Gambar 9). 


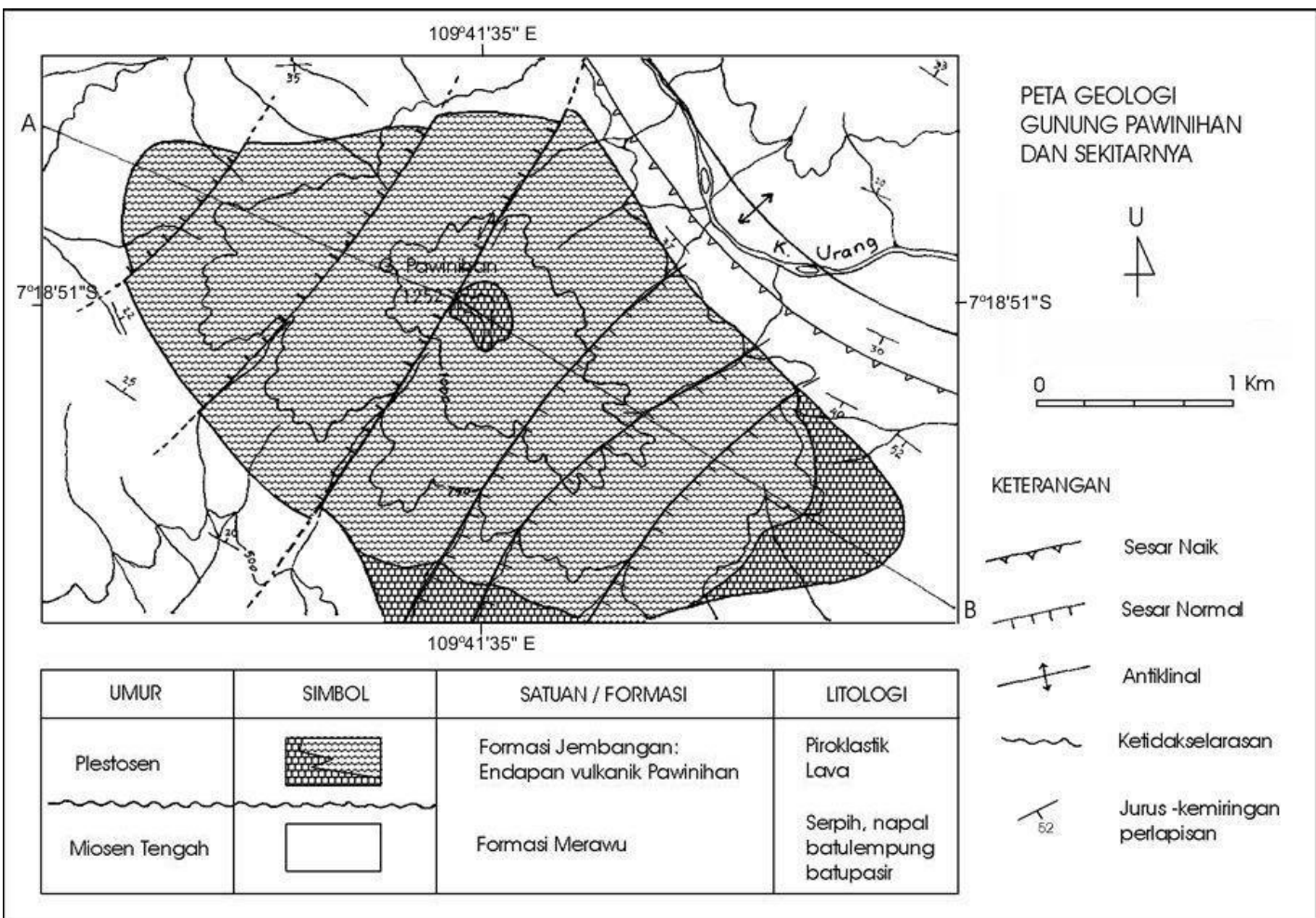

Gambar 7. Peta Geologi Gunung Pawinihan dan Sekitarnya

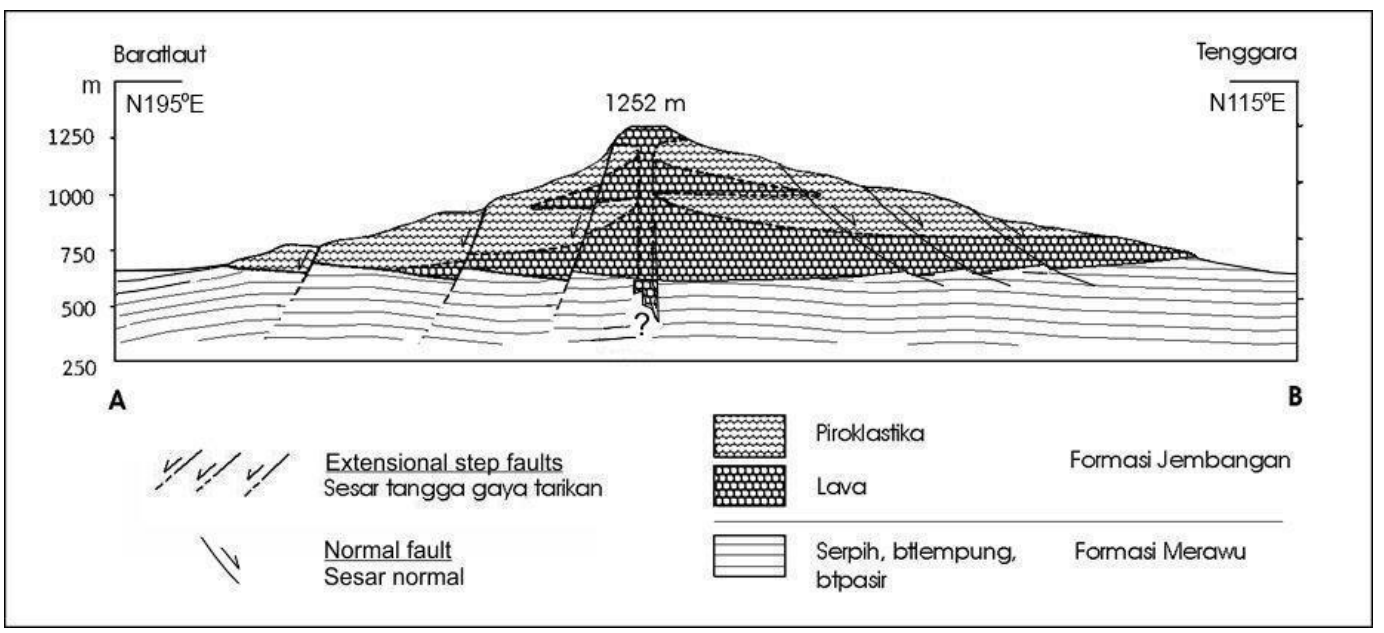

Gambar 8. Penampang Geologi Gunung Pawinihan: Perhatikan posisinya yang "mengambang" di atas Formasi Merawu 


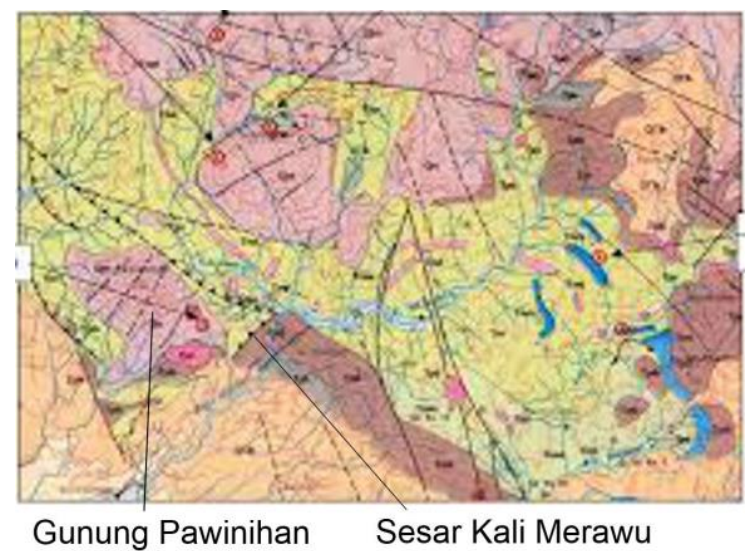

Gambar 9. Posisi Sesar Kali Merawu yang berada di sebelah Tenggara Gunung Pawinihan (Condon, dkk, 1996)

\subsection{Gerakan Massa dan Tektonik Gayaberat}

Secara fisik Formasi Merawu merupakan batuan yang bersifat plastik dan lentur. Batuan ini bersifat kedap air, dengan harga konduktivitas hidrolika kecil (Tabel 2). Bila jenuh air, ia akan licin, dapat membentuk lumpur, dengan berat jenis (specific gravity) antara 2,0 - 2,25. Sementara itu endapan Pawinihan mempunyai karakter berat, keras, tebal rata-rata $=$ $300 \mathrm{~m}$, luas sebaran lebih kurang 2,375 $\mathrm{km} \mathrm{x} \mathrm{4,25} \mathrm{km}=10,09 \mathrm{~km}^{2}=10.090 .000 \mathrm{~m}^{2}$, dengan berat jenis 2,7 - 2,9 (Tabel 2). Keberadaan Gunung Pawinihan di atas Formasi Merawu secara umum dapat diidentikkan dengan suatu massa tebal dan luas dengan nilai berat jenis cukup besar, selanjutnya menimbulkan gaya berat besar di atas bidang miring sebagaimana model distribusi gaya pada Gambar 10.

Tabel 2 Sifat Fisik Litologi Formasi Merawu dan Formasi Jembangan

\begin{tabular}{llll}
\hline Satuan Litostratigrafi & Litologi & Berat Jenis & $\begin{array}{l}\text { Konduktivitas Hidrrolika } \\
\text { (Todd, 1980) }\end{array}$ \\
\hline Formasi Merawu & $\begin{array}{l}\text { napal, serpih, batupasir, } \\
\text { batulempung }\end{array}$ & $0,0002-0,2 \mathrm{~m} / \mathrm{hari}$ \\
Formasi Jembangan & $\begin{array}{l}\text { breksi } \quad \text { piroklastik, 2, 2, }-2,9 \\
\text { batupasir vulanik, lava }\end{array}$ & $0,01-0,2 \mathrm{~m} / \mathrm{hari}$ \\
\hline
\end{tabular}

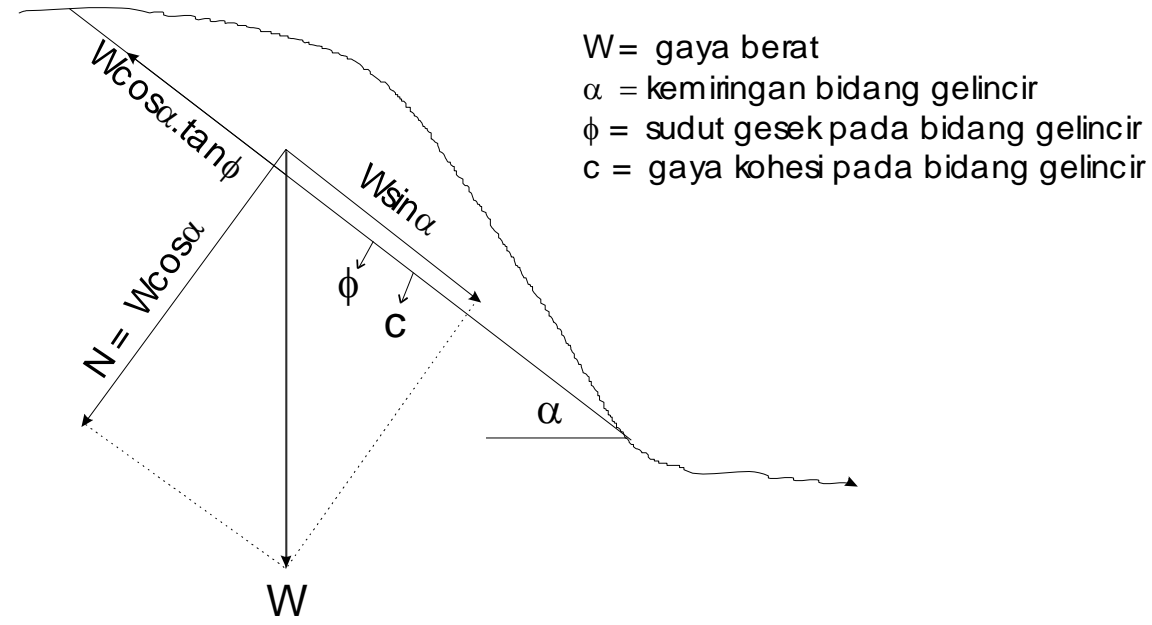

Gambar 10. Distribusi Gaya pada Suatu Massa yang Bertumpu di atas Bidang Miring (Goodman, 1989)

Formasi Jembangan pada umumnya mempunyai ketebalan mencapai lebih dari $300 \mathrm{~m}$, dengan soil yang tebal (mencapai $>5 \mathrm{~m}$ ), penyebarannya cukup luas yaitu lebih dari $16 \times 20 \mathrm{~km}^{2}$. Batuan yang tebal berat dan mempunyai densitas besar 
ini bertumpu di atas Formasi Merawu yang lunak, plastis, dan licin bila jenuh air. Ditunjang oleh adanya medan orografis yang secara umum miring ke Selatan, maka terjadilah gejala-gejala gelinciran, lengseran, longsoran, amblesan, dan rayapan tanah/batuan. Gunung Telagalele, Gunung Pawinihan, dan Gunung Lumbung pun ikut merayap ke arah depresi Serayu di Selatan (Van Bemmelen, 1949, Kusumayudha \& Purwanto, 2020).

Sesar-sesar normal berjenjang di bagian Baratlaut Pawinihan menunjukkan bekerjanya gaya ekstensional akibat adanya gerakan ke arah yang berlawanan, ke Tenggara. Di Tenggara terdapat topografi yang lebih rendah, yaitu lembah Kali Merawu. Pada lembah tersebut terdapat sesar naik (Condon, dkk, 1996; Kusumayudha \& Purwanto, 2020), diperkirakan sesar tersebut dipengaruhi oleh adanya gerakan Gunung Pawinihan ke Tenggara, yang mendorong batuan plastis Merawu menjadi tersesarkan mengikuti bidang lemah yaitu bidang perlapisan. Model gerakan-gerakan massa Gunung Pawinihan terjadi dalam bentuk sesar-sesar berjenjang, gelinciran batuan vulkanik di atas lempung, dan longsoran kompleks yang melibatkan batuan tumpuan dan mengaktifkan sesar naik sebagaimana terlihat di dalam Gambar 11. Salah satu longsor besar Pawinihan terjadi pada tahun 2006, ke arah Timur, menimpa sisi jalan dan daerah permukiman (Badan Geologi, 2018). Kondisi lereng yang longsor mempunyai kemiringan sekitar $45^{\circ}-60^{\circ}$ (Naryanto, dkk, 2017), disusun oleh endapan vulkanik Pawininhan dalam kondisi lapuk. Jenis gerakan adalah tipe kompleks, termasuk kombinasi rotasional dan translasional, serta aliran (Kusumayudha \& Purwanto, 2020).

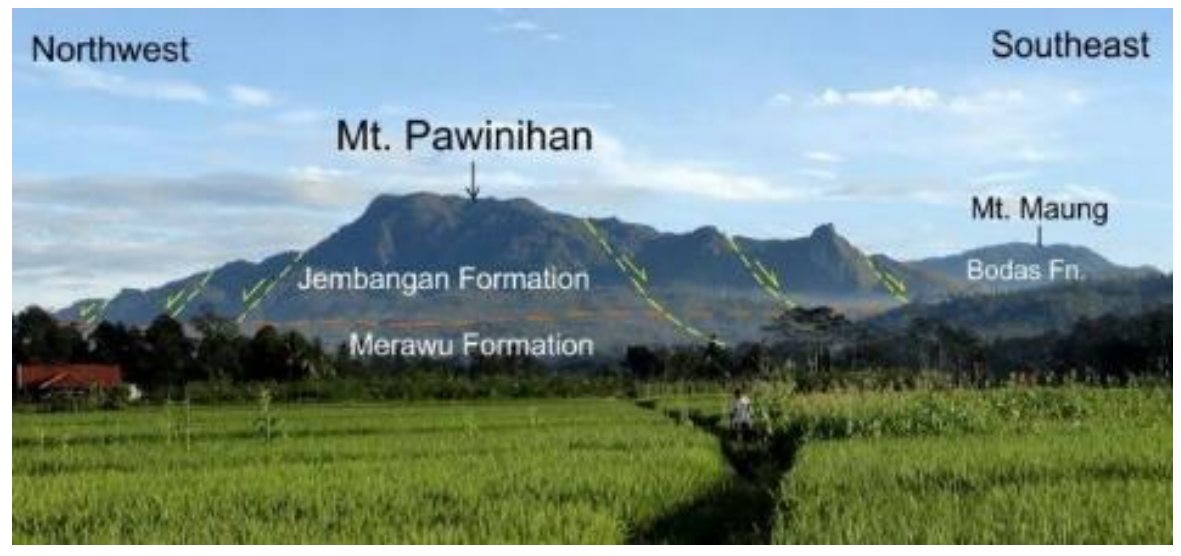

Gambar 11. Interpretasi Sesar-sesar Berjenjang pada Gunung Pawinihan (Kusumayudha \& Purwanto 2020, revisi)

Pada tahun 1931 - 1936 Van Bemmelen melakukan pengukuran kedudukan puncak-puncak gunung dan bukit yang terdapat di Daerah Karangkobar, yaitu Gunung Telagalele, Gunung Lumbung, dan Gunung Pawinihan, secara periodik. Hasil pengukuran tersebut menunjukkan bahwa Gunung Telagalele bergerak relatif ke arah Selatan dengan kecepatan rata-rata $40 \mathrm{~cm} / \mathrm{th}$, sedangkan Gunung Pawinihan $24 \mathrm{~cm} / \mathrm{th}$ (Van Bemmelen, 1949). Berdasarkan penelitian ini Van Bemmelen menyatakan bahwa di daerah Karangkobar terjadi gliding tectonic akibat pengaruh gaya berat, yang tercermin dari banyak dijumpainya sesar naik dan sesar normal berjenjang, amblesan, lengseran, dan longsoran massa batuan (Kusumayudha \& Purwanto, 2020). Seluruh tubuh Gunung Pawinihan sendiri diduga telah terlepas dari tambatannya (volcanic feeding-neck), dan tergelincir menuju depresi Kali Serayu (Van Bemmelen, 1949, hal 610).

Bukti lain terjadinya pergeseran Gunung Pawinihan juga tercermin dari hasil penelitian yang dilakukan pada tahun 1980/1981, dimana puncak Pawinihan teridentifikasi berada pada koordinat $7^{\circ} 18^{\prime} 40^{\prime \prime}$ LS dan $109^{\circ} 41^{\prime} 30^{\prime \prime}$ BT (Sari Bahagiarti K., 1981, tidak dipublikasikan). Padahal data penentuan lokasi berdasarkaan Google Earth saat ini, puncak Pawinihan menunjukkan koordinat $7^{\circ} 18^{\prime} 51^{\prime \prime}$ LS dan $109^{\circ} 41^{\prime} 35^{\prime}$ " BT. Dengan mengacu pada 1 detik lintang/bujur $=$ 30,9227 m, maka dalam kurun waktu 40 tahun telah terjadi pergeseran posisi Gunung Pawinihan sebesar 11", lebihkurang 340,1497 m, atau 8,5 m/tahun ke arah Selatan, dan 5", sekitar 154,6135 m, atau 3,8 m/tahun ke arah Timur. Dengan demikian pergerakan Gunung Pawinihan rata-rata 9,3 m/tahun ke Tenggara, tepatnya arah $\mathrm{N} 155^{\circ} 5^{\prime} 15^{\prime \prime} \mathrm{E}$ (Tabel 3, Gambar 12).

Angka-angka tersebut tentu sangat fantastik, namun demikian bukan tidak mungkin bahwa memang telah terjadi perpindahan letak trianggulasi puncak Gunung Pawinihan. Untuk memastikan kebenaran hal tersebut, perlu dilakukan pembuktian dan penelitian lebih lanjut dengan menggunakan metode dan instrumen yang lebih canggih. 
54 ISSN 2549-7197 (cetak), ISSN 2549-564X (online)

JMEL, Volume 4 Nomor 2, 2020

Tabel 3. Perhitungan Pergeseran posisi Gunung Pawinihan sejak 1980/1981 hingga 2020

\begin{tabular}{|c|c|c|c|c|c|}
\hline Tahun & Koordinat & & Pergeseran & & \\
\hline & LS & BT & ke Selatan & ke Timur & ke Tenggara \\
\hline $1980 / 1981$ & $7^{\circ} 18^{\prime} 40^{\prime \prime}$ & $109^{\circ} 41^{\prime} 30^{\prime \prime}$ & \multirow{2}{*}{$\begin{array}{l}11 "=340,1497 \mathrm{~m} \\
\text { atau } 8,5 \mathrm{~m} / \mathrm{th}\end{array}$} & \multirow{2}{*}{$\begin{array}{l}5 "=154,6135 \mathrm{~m} \\
\text { atau } 3,8 \mathrm{~m} / \mathrm{th}\end{array}$} & \multirow{2}{*}{$\begin{array}{l}\sqrt{ }\left[(8,5)^{2}+(3,8)^{2}\right]= \\
9,3 \mathrm{~m} / \mathrm{th} ; \\
\mathrm{N} 155^{\circ} 5^{\prime \prime} 15^{\prime \prime} \mathrm{E}\end{array}$} \\
\hline 2020 & $7^{\circ} 18^{\prime} 51^{\prime \prime}$ & $109^{\circ} 41^{\prime} 35^{\prime \prime}$ & & & \\
\hline
\end{tabular}

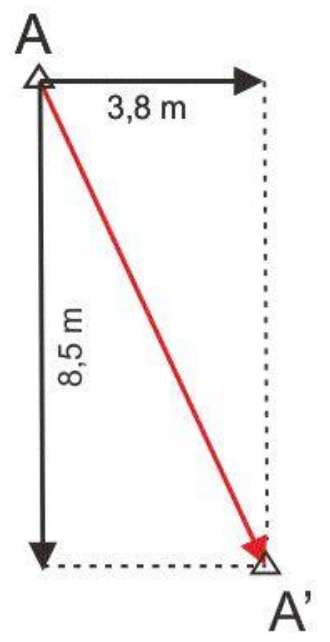

\section{A : Puncak Pawinihan tahun 1980/1981 \\ 7018'40" LS, 109041'30" BT}

\author{
A': Puncak Pawinihan \\ tahun 2020 \\ 7018'51" LS, 109041'35" BT
}

\section{Arah dan Besaran \\ Pergeseran}

Gambar 12. Pergeseran Puncak Gunung Pawinihan dari Tahun 1980/1981 - 2020: N1555'15”E, 9,3 m/tahun

Sesar-sesar normal bertangga dengan gerak normal ke arah Baratlaut diduga merupakan akibat dari gerak lengser seluruh tubuh gunung ini ke arah depresi Kali Merawu di Selatan-Tenggara Gunung Pawinihan. Kali Merawu sendiri merupakan anak Sungai Serayu di Selatan Zona Serayu Utara. Didasarkan atas data geologis yang ada, sesar ekstensional, sesar normal berjenjang di Tenggara, sesar naik Kali Merawu, antiklin, dan sifat fisik batuan endapan Pawinihan maupun endapan Merawu, serta longsor yang menimpa desa Sijeruk, maka dapat disusun model konseptual gerak gravitasional Gunung Pawinihan sebagaimana Gambar 13.

Hasil penelitian ini diharapkan dapat dijadikan sebagai bahan informasi, dan referensi bagi semua pihak tekait, serta untuk rujukan dalam upaya mitigasi bencana. Riset dan penelitian-penelitian lanjutanpun perlu terus dilakukan, agar evolusi geologi dan tektonik gayaberat di Gunung Pawinihan dan sekitarnya pada khususnya, serta Zona Serayu Utara pada umumnya dapat digali dengan sebaik-baiknya untuk memperkaya khasanah ilmu pengetahuan di Indonesia. 


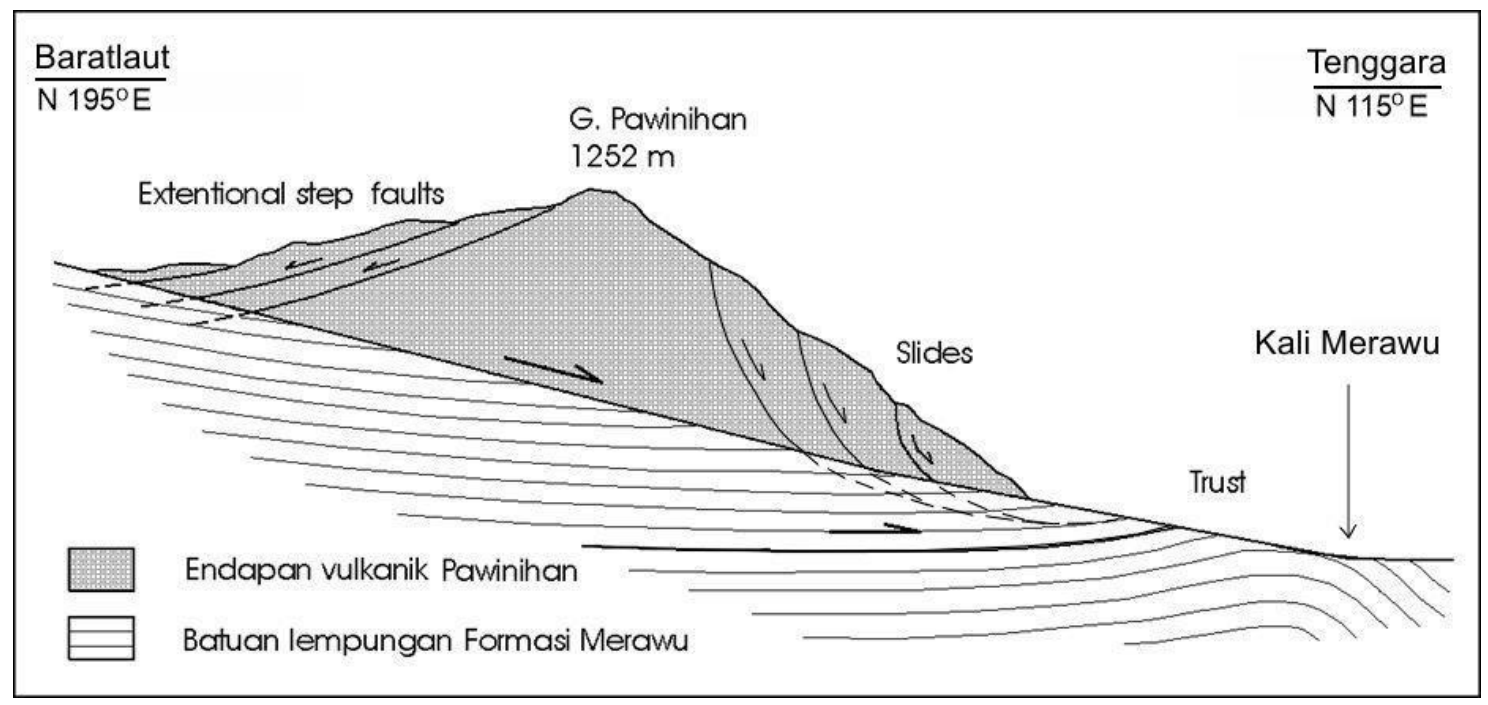

Gambar 13. Model Tektonik Gayaberat Gunung Pawinihan

\section{KESIMPULAN}

Kesimpulan yang dapat ditarik dari penelitiaan ini adalah sebagai berikut:

1. Bentuklahan daerah penelitian dapat diklasifikasikan dalam Satuan Morfologi Gunung dan Satuan Morfologi Bergelombang. Secara stratigrafi Gunung Pawinihan disusun oleh breksi, batupasir vulkanik, tufa, dan lava Formasi Jembangan, bertumpu secara tidak selaras di atas Formasi Merawu, terdiri dari napal, serpih, dan batulempung. Struktur geologi yang dijumpai adalah sesar-sesar normal ekstensional dengan jurus TimurlautBaratdaya, dan sesar-sesar normal berjenjang dengan jurus Baratdaya-Timurlaut, sesar naik Kali Urang, serta antiklin Kali Urang.

2. Berdasarkan hasil identifikasi posisi puncak Gunung Pawinihan pada tahun 1980/1981 dan saat ini, telah terjadi

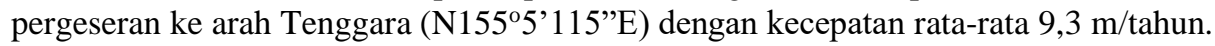

3. Gunung Pawinihan mengalami gerak tektonik dan mekanik yang diakibatkan oleh gayaberat massa batuan bertumpu pada bidang miring yang lembek dan licin. Gerakan dikendalikan oleh perbedaan sifat fisik yang kontras antara endapan vulkanik Pawinihan, berat jenis 2,7 - 2,9, ketebalan endapan rata-rata $300 \mathrm{~m}$, luas endapaan lebih-kurang $10.090 .000 \mathrm{~m}^{2}$, dengan endapan lempungan Merawu mempunyai berat jenis $2.0-2,25$.

4. Gerakan gravitasional Gunung Pawinihan dan gelinciran kearah Timur telah mendorong sesar naik Kali Urang, di sisi lain longsor-longsor bagian tubuh gunung ke arah Tenggara telah mendorong Sesar Naik Kali Merawu.

\section{UCAPAN TERIMA KASIH}

Penghargaan dan ucapan terima kasih disampaikan kepada Direktorat Penelitian dan Pengabdian kepada Masyarakat Direktorat Jenderal Pendidikan Tinggi, Kementerian Pendidikan dan Kebudayaan Republik Indonesia yang telah memberikan pendanaan terhadap penelitian ini. Terima kasih juga untuk Lembaga Penelitian dan Pengabdiaan kepada Masyakat Universitas Pembangunan Nasional 'Veteran' Yogyakarta atas dukungan dan fasilitas yang disediakan selama pelaksanaan penelitiaan..

\section{DAFTAR PUSTAKA}

Badan Geologi (2018). Report on Mass Movement Investigation of Karangkobar District, Banjarnegara Regency, Central Java, Kementrian Energi dan Sumberdaya Mineral

Bachri, S. (2012), Batuan Asal dan Alas Formasi Paleogen Cekungan Serayu (provenance and basement of the paleogene formation in the serayu basin, Jurnal Geologi dan Sumberdaya Mineral, Vol 22, No.1: 15-23

Bachri, S. (2010), Pengaruh Kegiatan Tektonik dan Gunungapi Terhadap Karakteristik Sedimentologi sedimen Neogen Awal Daerah Bagian Tengah Cekungan Serayu, Jurnal Geologi dan Sumberdaya Mineral, Vol 20, No.4; 199-208 
56 ISSN 2549-7197 (cetak), ISSN 2549-564X (online)

JMEL, Volume 4 Nomor 2, 2020

Blow W.H. (1969). Late Middle Miocene to Recent Planktonic Foraminiferal Biostratigraphy, Proceedings First International Conference on Planktonic Microfossil, Geneva, 1967, 1:119-442

Condon, W.H., Pardyanto, L., Ketner, K.B., Amin, T.C., Gafoer S., dan Samodra. H. (1996) Peta Geologi Lembar Banjarnegara dan Pekalongan, Jawa Tengah, Badan Beologi, Bandung,

De Jong, K. A., 1973, Gravity and tectonics, John Wiley 7 Sons, New York

Dessaunettes, J.R. (1977), Catalogue of landforms for Indonesia, Soil Research Institute Ministry of Agriculture Agency for Research Development

Goodman, R. E. (1989), Introduction to Rock Mechanics, John Wiley \& Sons, New York

Hidayat R. (2018). Engineering Geological Condition of the Landslide Vulnerable Area of Karangkobar, Banjarnegara Regency, Proceedings Seminar Nasional Teknik Sipil, Universitas Muhammadiyah Surakarta.

Husein, S., Jyalita, J., Nursecha, M.A.Q. (2013), Kendali Stratigrafi dan Struktur Gravitasi pada Rembesan Hidrokarbon Sijenggung, Cekungan Serayu Utara, Prosiding Seminar Nasional Kebumian Ke-6, Teknik Geologi Universitas Gadjah Mada, Pros.

Hutomo, I. A., Maryono (2017). Prediction Model of Landslide in Karangkobar District, Jurnal Pembangunan Wilayah dan Kota, 12(3), 303-314.

Kusumayudha, S. B. \& S. Koesnaryo (2001), Fenomena Longsoran di Jawa Tengah DIY, Ditinjau dari Sudut Geologi Teknik: Diperlukan penanggulangan secara sosial-budaya, Buletin Teknologi Mineral (BTM)

Kusumayudha S.B. (2002). Geomechanical Characteristic of landslides in Central Java and DIY, Buku Sumberdaya Geologi DIY dan Jawa Tengah, IAGI Pengda Yogyakarta - Jateng.

Kusumayudha, S.B., Purwanto, H.S. (2020), Enormous Mass Movements, and Gravitational Tectonics Model of the North Serayu Mountains, Karangkobar Area, Banjarnegara Regency, Central Java, Indonesia, International Conference on Geology and Civil Engineering, Pros.

Martosuwito, S., Bachri, S., Kamal, Z.A. (2018) Stratigraphical and Sedimentological Review of the Merawu Formation, Serayu Basin, Central Jawa, Indonesia, Indonesian Journal on Geoscience, 5(2), 117-128. DOI: 10.17014/ijog.5.2.117-128

Naryanto, H. S. (2017). Analysis on Landslide Disaster of Jemblung Village 12 December 2014, Karangkobar District, Banjarnegara Regency, Central Java), Jurnal Alami, 1(1).

Phleger F.B (1951), Ecology of North Gulf of Mexico, The Geology society of America, Memoir 46

Todd, D.K. (1980) Groundwater Hydrology, John Wiley \& Sons, California.

Van Bemmelen, R. W. (1949), The Geology of Indonesia, Vol I A, Martinus Nijhoff, The Hague 